Supplement of Nat. Hazards Earth Syst. Sci. Discuss., 3, 3955-3966, 2015

http://www.nat-hazards-earth-syst-sci-discuss.net/3/3955/2015/

doi:10.5194/nhessd-3-3955-2015-supplement

(C) Author(s) 2015. CC Attribution 3.0 License.

(c) (i)

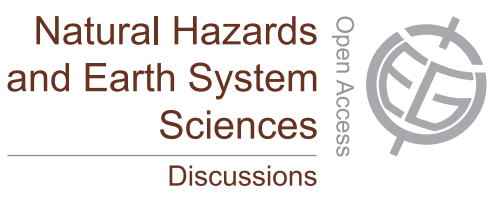

Supplement of

\title{
Brief Communication: Sendai Framework for Disaster Risk Reduction - success or warning sign for Paris?
}

\section{J. Mysiak et al.}

Correspondence to: J. Mysiak (jaroslav.mysiak@ feem.it)

The copyright of individual parts of the supplement might differ from the CC-BY 3.0 licence. 


\section{Supplement}

\section{Target \\ Zero-draft as on 20/10/2014 [SFDRR-0] Pre-conference \\ as \\ on 28/01/2015 \\ Final text released on 18/03/2015 \\ [SFDRR-1] \\ [SFDRR]}

[1] Mortality Reduce disaster mortality by [a given [a] Substantially reduce disaster Substantially reduce global disaster percentage in function of number of mortality [per capita] by 2030 [to mortality by 2030 , aiming to lower

hazardous events] by $20[\mathrm{xx}]$ achieve a minimum average global average per 100,000 global mortality mortality from disasters between 2020 between 2020-2030 compared to 2005and 2030 lower than the average 2015.

mortality between 2005 and 2015.]

[b] Substantially reduce disaster mortality [per capita] by 2030. [FN] To achieve this target, the minimum average global mortality from disasters between 2020 and 2030 should be lower than the average mortality between 2005 and 2015.

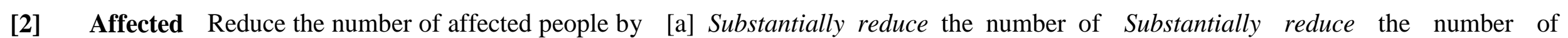
people [a given percentage in function of affected people per capita at the global affected people globally by 2030, aiming number of hazardous events] by $20[\mathrm{xx}]$. level by 2030. [FN] To achieve this to lower the average global figure per target, the minimum average of number 100,000 between 2020-2030 compared of affected people from disasters to 2005-2015. [FN] Categories of 
between 2020 and 2030 should be lower than the average number of affected people between 2005 and 2015 .

[b] Substantially reduce the number of affected people per capita at the global level by 2030. [FN] Categories of affected people will be considered/elaborated/agreed in the process for post Sendai work to be decided upon by the Conference. affected people will be elaborated in the process for post Sendai work decided by the Conference.

[3] Economic Reduce disaster economic loss by [a Reduce direct disaster economic loss in Reduce direct disaster economic loss in

[3] Economic Reduce disaster economic loss by [a Reduce direct disaster economic loss in Reduce direct disaster economic loss in loss given percentage in function of number elation to global gross domestic product of hazardous events] by $20[\mathrm{xx}]$. (GDP) by 2030. (GDP) by 2030 .

[4] Critical Reduce disaster damage to health and [a] Substantially reduce disaster damage infrastructure educational facilities by $[\mathrm{a}$ given percentage in function of number of hazardous events] by $20[\mathrm{xx}]$. to critical infrastructure, particularly health and educational facilities [by a given percentage] by 2030 .
Substantially reduce disaster damage to critical infrastructure and disruption of basic services, among them health and educational facilities, including through developing their resilience by 2030 .

[b] Substantially reduce disaster damage

to critical infrastructure and disruption of 
basic services, among them health and

educational facilities, including through

developing their resilience by 2030 .

[5] DRR Increase number of countries with Substantially increase the number of Substantially increase the number of strategies national and local strategies by [a given percentage] by $20[\mathrm{xx}]$.

countries with national and local disaster countries with national and local disaster risk reduction strategies by 2020. risk reduction strategies by 2020 .

[Increase by a given percentage accordingly with national capacities the number of national instruments to reduce direct disaster economic loss by 2030].

[6]

International

cooperation [a] [Substantially] enhance international cooperation in support of disaster risk reduction [[in/to ] developing countries/from developed to developing countries], including through providing adequate, [additional and] timely and predictable financial resources, technical assistance, technology transfer, capacity building and training programmes, [in order to enhance resilience to disasters and implement the framework/for the implementation of the framework] [by
Substantially enhance international cooperation to developing countries through adequate and sustainable support to complement their national actions for implementation of this framework by 2030 
xx \% by 2030].

[b] Enhance international cooperation to mobilize [a variety of necessary resources of its implementation of the framework particularly by developing] [adequa-te/effective] and sustainable support for the implementation of the framework particularly [by/in] developing countries. [FN] To achieve this target, minimum average international cooperation to developing countries for disaster risk reduction between 2020 and 2030 should be higher than average international cooperation between 2005 and 2015

\begin{tabular}{ll}
\hline [7] Early - & [a] Substantially increase the availability Substantially increase the availability of \\
warning & of and access to multi-hazard early and access to multi-hazard early warning \\
systems and & warning systems and disaster risk systems and disaster risk information and \\
risk & information and assessments to the assessments to the people by 2030. \\
assessments & people by 2030. \\
& [b] To develop specific multi-hazard \\
& early warning systems and to increase \\
\hline
\end{tabular}


availability and access of people to

information related to disaster risk. 